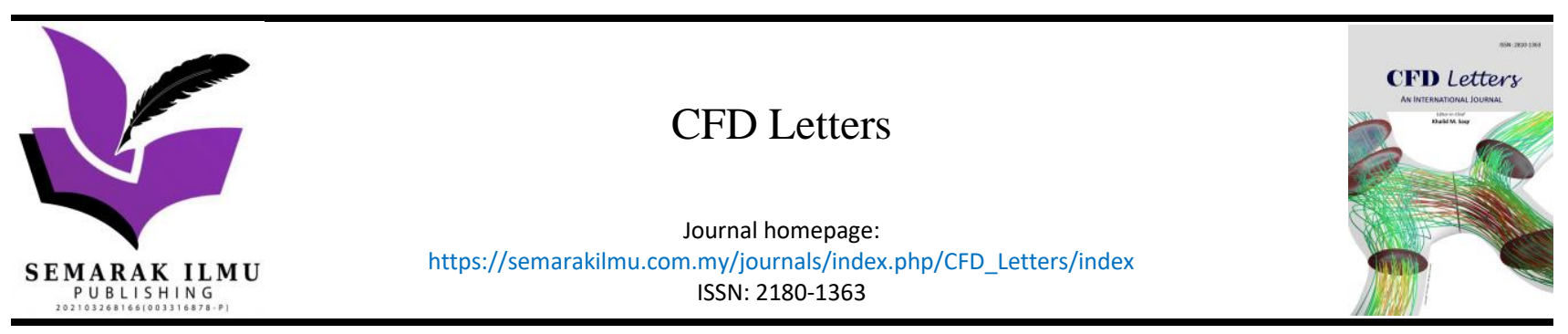

\title{
Flow Behaviour Assessment of Smokey SAM Rocket Prototype
}

\author{
Nur Azam Abdullah ${ }^{1,}$, Nor Izzuddin Ismail ${ }^{1}$, Izham Izzati Ismail ${ }^{1}$, Muhammad Hanafi Azami ${ }^{1}$, \\ Norhuda Hidayah Nordin², Nor Aiman Sukindar ${ }^{2}$, Zulkifli Zainal Abidin ${ }^{3}$, Ahmad Joahari Abu Bakar ${ }^{4}$, \\ Noriza Dani ${ }^{4}$ \\ 1 Department of Mechanical Engineering, Kulliyyah of Engineering, International Islamic University Malaysia, Jalan Gombak, 53100, Kuala Lumpur \\ Malaysia \\ 2 Department of Manufacturing and Material Engineering, Kulliyyah of Engineering, International Islamic University Malaysia, Jalan Gombak, 53100 \\ Kuala Lumpur, Malaysia \\ 3 Centre for Unmanned Technologies (CUTe), International Islamic University Malaysia, Jalan Gombak, 53100, Kuala Lumpur, Malaysia \\ 4 Lestari Aero Industries Sdn Bhd, Level 15, DPulze, Lingkaran Cyber Point Timur, Cyberjaya, 63000 Cyberjaya, Selangor, Malaysia
}

\section{ARTICLE INFO}

\section{Article history:}

Received 14 August 2021

Received in revised form 2 September 2021

Accepted 9 September 2021

Available online 13 September 2021

\section{Keywords:}

Smokey-SAM; aerodynamic; CFD; flight performance; rocket trajectory

\section{ABSTRACT}

This paper presents an aerodynamic assessment on the "Smokey Sam Prototype (TRL6) Start $(X)$ ". Initially, the rocket prototype was designed using OpenRocket open source software, where all of the user's design requirements and objectives are considered. The TRL-6 Smokey Sam Star (X) is expected to fly within $400 \mathrm{~m}$ with the operating Mach 0.2, as comparable to US GTR-18A. This research evaluates the aerodynamics performance of the design Smokey Sam prototype rocket using a computational fluid dynamics (CFD) approach. For instance, the CFD study assessed the flight performance and stability once launched, such as lift coefficient, drag coefficient and pitching moment. This research employs K-omega $(k-\omega)$ model to express the turbulent properties of the flow. The actual pressure distribution was compared with the conventional rocket material's exact pressure distribution to inspect the best rocket material to sustain the best strength to weight ratio at highspeed trajectory operation. Several observations were made into the modelling process, such as surrounding velocity and pressure. It is found that the flight is in stable mode since the obtained pitching moments are almost zero at all assessed speeds.

\section{Introduction}

One of the most popular in the current development in rocket design is a sounding rocket where sounding rocket has been broadly employed in the space program to send large and substantial payloads to such high elevation from the earth. impinging jet to the flat [1]. In another related offset program [2], preliminary investigations on a pivoting detonation rocket engine for flight demonstration using a sounding rocket have attracted attention since it could be extended for future upper stage due to its outstanding theoretical efficiency and short combustor length. A research conducted by Okninski et al., [3] managed to design a sounding rocket that carried a CanSat payload

\footnotetext{
* Corresponding author.

E-mail address: azam@iium.edu.my (Nur Azam Abdullah)
} 
model that desired to be containable in soda containers of $350 \mathrm{ml}$ volume with a launch magnitude of up to $500 \mathrm{~g}$. It is highly to be remarked that the rocket was propelled by reusable composite solid rocket motors that will execute it for small scientific operations to be carried to altitudes of skyward to $10 \mathrm{~km}$.

A hybrid sounding rocket has been expanded to integrate safety during handling. It launches operations at an economical expense in a much-advanced approach, including controllable thrust including locked off and restart aptitude, further improvements in the sounding rocket application [4]. Several tests have been conducted to obtain an optimal design of sounding rocket for the carried payloads, such as; within the weak equivalence principle (WEP) [5] during the free-fall part of the flight of a sounding rocket payload, thermal and mechanical configuration of the Matter-wave Interferometry in Microgravity (MAIUS) atom interferometer sounding rocket payload on nominal VSB-30 sounding rocket [6]. In more advanced utilisation, the robust design of the MAIUS atom interferometer has been developed by arranging micro-integrated distributed feedback (DFB) diode laser modules, including free-space optical bench technology [7]. An interesting insight through the stress investigation of a thick-walled cylinder for a rocket motor case under internal pressure has been carried out [8]. The study was conducted to establish a highly durable casing that can withstand high pressure and temperature.

The k-omega turbulence model was first postulated by Kolmogorov in 1942 and later independently by Saffman in 1970 [9]. The model solves two turbulence transport equations for the turbulent kinetic energy $k$ and the specific dissipation rate $\omega$; it has been employed to several cases such as, impinging jet to the flat [10], sonic boom generated by a slender body [11], side force formulation and its alleviation over a slender body [12]. The model has a basic formulation for fully turbulent flows that satisfy the law of the wall without knowledge of the distance to the wall or complicated near-wall damping terms. On the other hand, an investigation of flow asymmetry around a slender body at high angles of attack was conducted to evaluate the requirement to use a nondissipative unbiased discretization scheme by implementing the Large Eddy simulation (LES) [13].

On another view, most of Wilcox's development of the model used boundary layer codes, but recently Menter has shown several applications to Navier-Stokes codes [14]. Menter found that the model exhibited a strong dependence on freestream values of $\omega$ and proposed a somewhat ad hoc fix. In this work, many of Menter's suggestions for the numerical implementation of the model have been used, but this consideration fix for freestream dependence. To be highlighted, in the event of studying the impact of turbulence modelling on external supersonic flow field simulations in rocket aerodynamics, the SST $k-\omega$ model has been picked as the most fitting one for this type of flow [15]. Menter's Shear Stress Transport (SST) turbulence model is a widely adopted and robust two-equation eddy-viscosity turbulence model employed in computational fluid dynamics (CFD). In such rocket studies, the CFD simulations have been examined either of intrinsic flow, such as the solid propellant rocket motor nozzle [16] or the extrinsic flow at the attached fins on the rocket body [17].

SST models exhibit less sensitivity to free stream conditions (flow outside the boundary layer) than many other turbulence models. The shear stress limiter helps the k-omega model avoid a buildup of excessive turbulent kinetic energy near stagnation points. The SST models provide a platform for additional extensions such as SAS and laminar-turbulence transition. The quasi-3-D form of the kequation has been derived by writing the $\mathrm{m}$ - and 0 momentum equations in non-conservative form, multiplying each by its fluctuating. The usual turbulence modelling approximations are made. The production term is written in terms of the vorticity magnitude using Menter's suggestion [18]. Source terms that arise from the quasi-3-D equations are neglected. The co-equation is derived from the kequation by dimensional considerations. With that relevant discussions, this paper proposes 
investigating the rocket's aerodynamics performance when speeding up since the aerodynamics investigation on the Smokey SAM prototype rocket has not been widely inquired.

\section{Methodology}

\subsection{Rocket Design Processes}

The design of a rocket was developed using an open-source rocket software named OpenRocket. Many designs have been illustrated ere the decided design been adopted. From observation, there is no specific equation to develop a rocket in a fully equipped dimension. However, to circumscribe specific components such as nose cone and fins, some equations can be used to achieve the desired design, as shown in Figure 1. A model rocket consists of several elements such as the nose cone, launch lug, parachute system, body tube, engine hook and other structure.

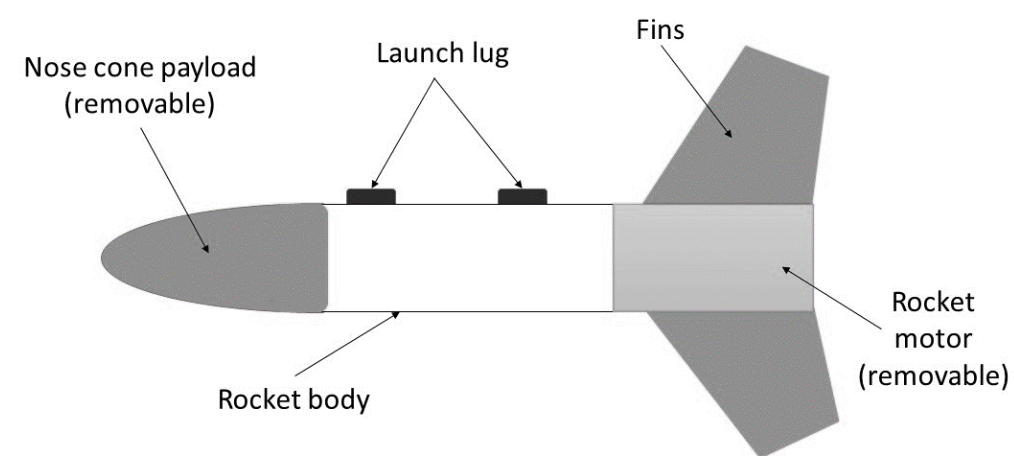

Fig. 1. Specific component of a typical sounding rocket

The basic in designing a rocket is based on its stability during a flight. In this view, the centre of gravity and the location of the centre of pressure are crucial parameters for this purpose. Figure 2 shows the conventional parameters required in designing a sounding rocket, rendered with Barrowman's Equation [19] as presented in Eqs. (1) and (2)

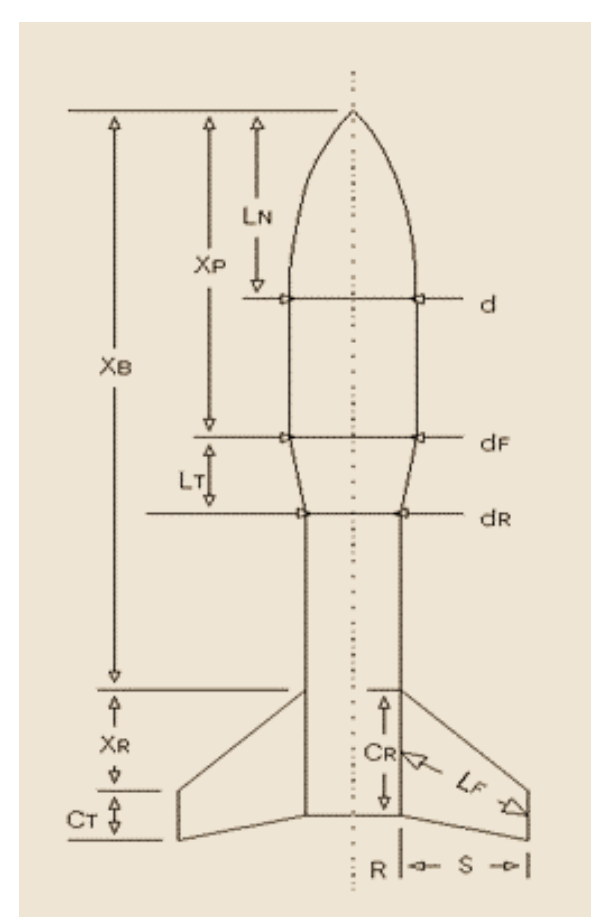

Fig. 2. Rocket design parameters based on Barrowman's concept 
$\left(C_{N}\right)_{F}=\left[1+\frac{R}{S+R}\right]\left[\frac{4 N\left(\frac{S}{D}\right)^{2}}{1+\sqrt{1+\left(\frac{2 L_{F}}{C_{R}+C_{T}}\right)^{2}}}\right]$

$X_{F}=X_{B}+\frac{X_{R}}{3} \frac{\left(C_{R}+2 C_{T}\right)}{\left(C_{R}+C_{T}\right)}+\frac{1}{6}\left[\left(C_{R}+C_{T}\right)-\frac{\left(C_{R} C_{T}\right)}{\left(C_{R}+C_{T}\right)}\right]$

where $L_{N}=$ length of nose, $d=$ diameter at base of nose, $d_{F}=$ diameter at front of transition, $d_{R}=$ diameter at rear of transition, $L_{T}=$ length of transition, $X_{P}=$ distance from tip of nose to front of transition, $C_{R}$ = fin root chord, $C_{T}=$ fin tip chord, $S=$ fin semispan, $L_{F}=$ length of fin mid-chord line, $R=$ radius of body at aft end, $X_{R}=$ distance between fin root leading edge and fin tip leading edge parallel to body, $X_{B}=$ distance from nose tip to fin root chord leading edge, and $N=$ number of fins.

Hence, the scheme of the applied methodology in investigating the performance of the design Smokey SAM rocket is presented as in Figure 3. The design process starts with the design requirements and objectives of the flight mission and assesses the aerodynamics point of view in Ansys Fluent. For a more comprehensive view, the design's geometric parameters through OpenRocket modelling are demonstrated in Table 1.

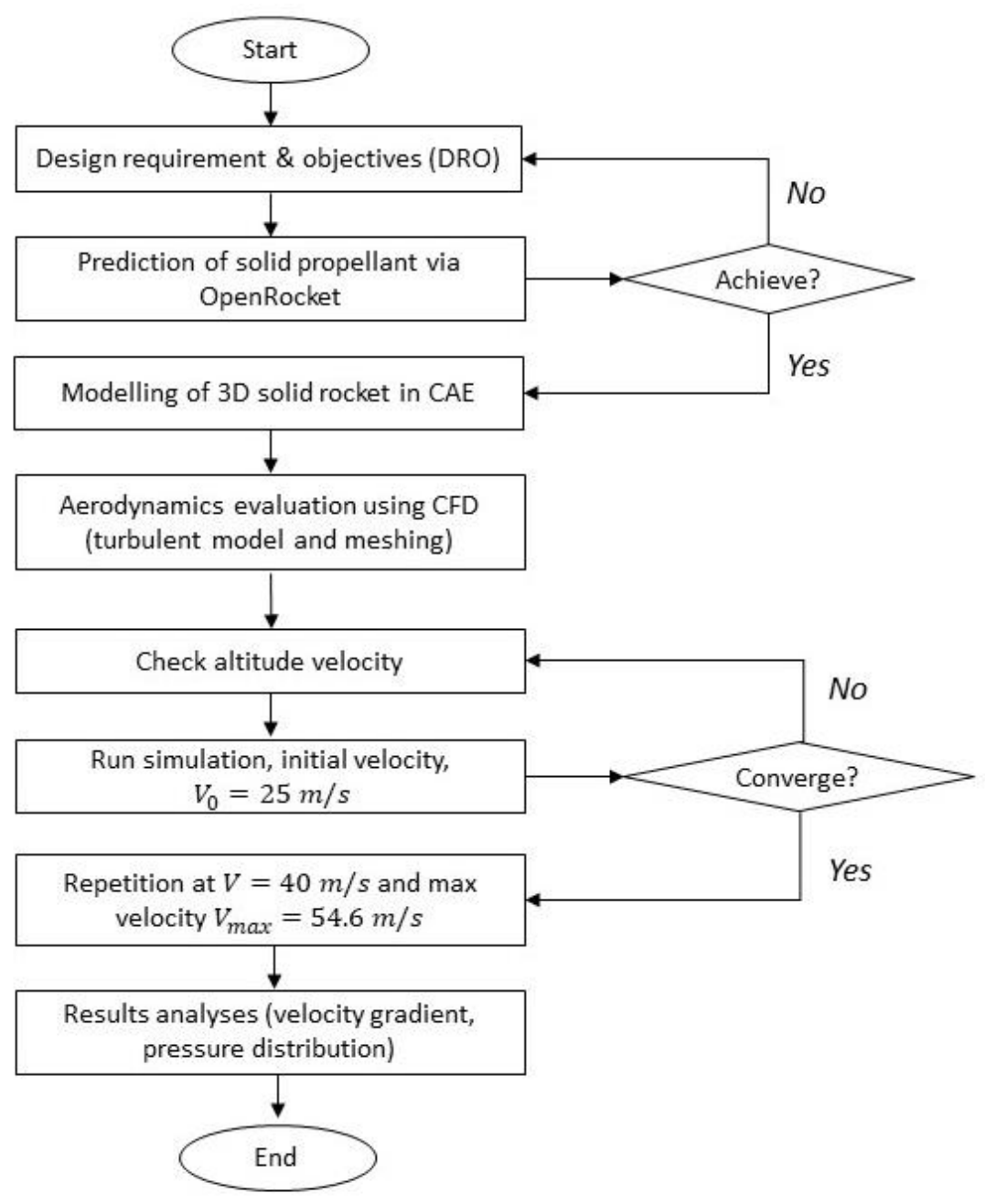

Fig. 3. Modelling scheme of the presented Smokey-SAM rocket 
Table 1

Geometric parameters of the design through OpenRocket modelling

\begin{tabular}{|c|c|c|c|c|c|}
\hline \multirow[t]{2}{*}{ Parameter } & \multicolumn{5}{|c|}{ Components } \\
\hline & $\begin{array}{l}\text { Nose } \\
\text { cone }\end{array}$ & $\begin{array}{l}\text { Body } \\
\text { tube }\end{array}$ & Fins & $\begin{array}{l}\text { Launch Lug } \\
1\end{array}$ & $\begin{array}{l}\text { Launch Lug } \\
2\end{array}$ \\
\hline Shape & Ellipsoid & $\mathrm{n} / \mathrm{a}$ & Trapezoidal & $\mathrm{n} / \mathrm{a}$ & $\mathrm{n} / \mathrm{a}$ \\
\hline Length $(\mathrm{cm})$ & 10.00 & 28.00 & $\mathrm{n} / \mathrm{a}$ & 3.00 & 3.00 \\
\hline Base diameter $(\mathrm{cm})$ & 5.00 & $\mathrm{n} / \mathrm{a}$ & $\mathrm{n} / \mathrm{a}$ & $\mathrm{n} / \mathrm{a}$ & $\mathrm{n} / \mathrm{a}$ \\
\hline Thickness (cm) & 0.20 & 0.30 & 0.20 & 0.10 & 0.10 \\
\hline Shoulder diameter $(\mathrm{cm})$ & 4.60 & $\mathrm{n} / \mathrm{a}$ & $\mathrm{n} / \mathrm{a}$ & $\mathrm{n} / \mathrm{a}$ & $\mathrm{n} / \mathrm{a}$ \\
\hline Shoulder length $(\mathrm{cm})$ & 3.00 & $\mathrm{n} / \mathrm{a}$ & $\mathrm{n} / \mathrm{a}$ & $\mathrm{n} / \mathrm{a}$ & $\mathrm{n} / \mathrm{a}$ \\
\hline Outer diameter $(\mathrm{cm})$ & $\mathrm{n} / \mathrm{a}$ & 5.00 & $\mathrm{n} / \mathrm{a}$ & 1.00 & 1.00 \\
\hline Inner diameter $(\mathrm{cm})$ & $\mathrm{n} / \mathrm{a}$ & 4.40 & $\mathrm{n} / \mathrm{a}$ & 0.80 & 0.80 \\
\hline Cross section & $\mathrm{n} / \mathrm{a}$ & $\mathrm{n} / \mathrm{a}$ & Square & $\mathrm{n} / \mathrm{a}$ & $\mathrm{n} / \mathrm{a}$ \\
\hline Number of fins & $\mathrm{n} / \mathrm{a}$ & $\mathrm{n} / \mathrm{a}$ & 5.00 & $\mathrm{n} / \mathrm{a}$ & $\mathrm{n} / \mathrm{a}$ \\
\hline Root chord (cm) & $\mathrm{n} / \mathrm{a}$ & $\mathrm{n} / \mathrm{a}$ & 7.00 & $\mathrm{n} / \mathrm{a}$ & $\mathrm{n} / \mathrm{a}$ \\
\hline Tip chord (cm) & $\mathrm{n} / \mathrm{a}$ & $\mathrm{n} / \mathrm{a}$ & 3.00 & $\mathrm{n} / \mathrm{a}$ & $\mathrm{n} / \mathrm{a}$ \\
\hline Height (cm) & $\mathrm{n} / \mathrm{a}$ & $\mathrm{n} / \mathrm{a}$ & 7.00 & $\mathrm{n} / \mathrm{a}$ & $\mathrm{n} / \mathrm{a}$ \\
\hline Sweep length $(\mathrm{cm})$ & $\mathrm{n} / \mathrm{a}$ & $\mathrm{n} / \mathrm{a}$ & 4.04 & $\mathrm{n} / \mathrm{a}$ & $\mathrm{n} / \mathrm{a}$ \\
\hline Sweep angle $\left({ }^{\circ}\right)$ & $\mathrm{n} / \mathrm{a}$ & $\mathrm{n} / \mathrm{a}$ & 30.00 & $\mathrm{n} / \mathrm{a}$ & $\mathrm{n} / \mathrm{a}$ \\
\hline Radial position $\left({ }^{\circ}\right)$ & $\mathrm{n} / \mathrm{a}$ & $\mathrm{n} / \mathrm{a}$ & $\mathrm{n} / \mathrm{a}$ & 40.00 & 40.00 \\
\hline $\begin{array}{l}\text { Position relative to top of parent component } \\
(\mathrm{cm})\end{array}$ & $\mathrm{n} / \mathrm{a}$ & $\mathrm{n} / \mathrm{a}$ & $\mathrm{n} / \mathrm{a}$ & 10.50 & 10.50 \\
\hline
\end{tabular}

The designed rocket was then remodelled using SolidWorks in order to use it for the CFD simulation. All views from Solidwork 3D modelling are presented as in Figures 4 and 5 . The designed Smokey SAM is not required to carry any payload yet, but essentially to produce thick cloudy smoke.

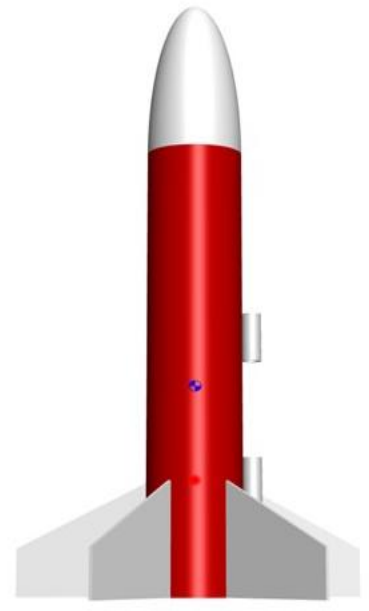

(a)

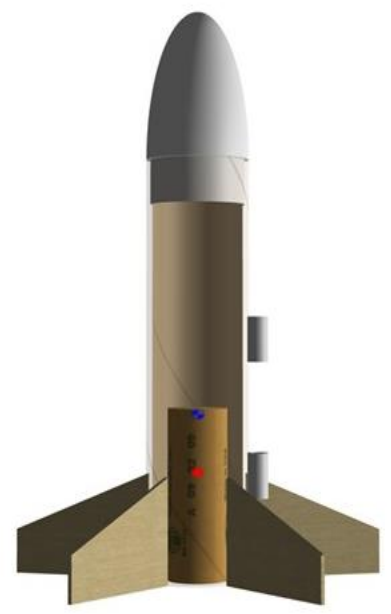

(b)

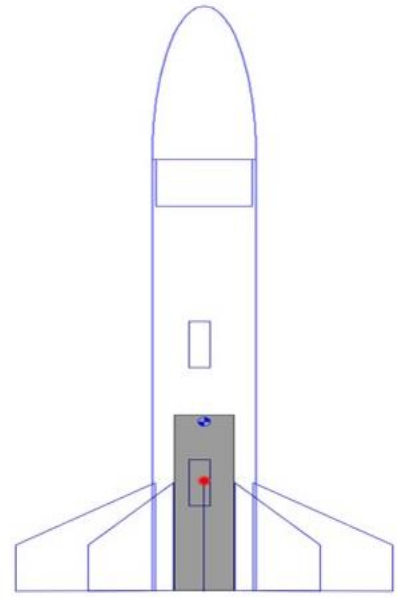

(c)

Fig. 4. Developed Smokey SAM model for CFD analysis 


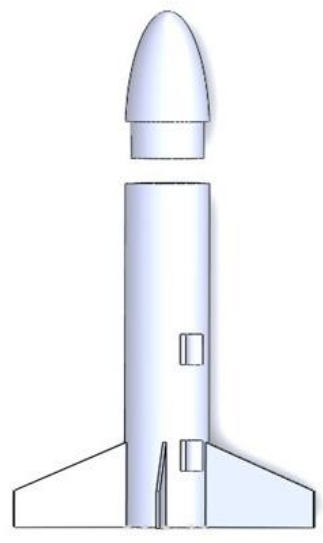

(a)

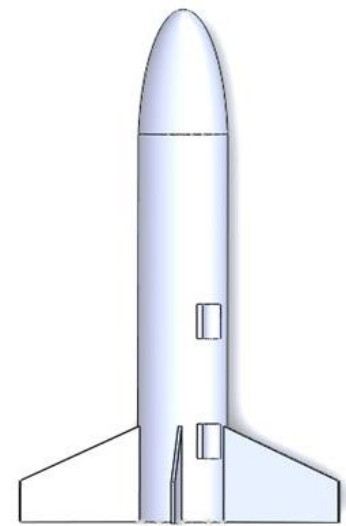

(b)

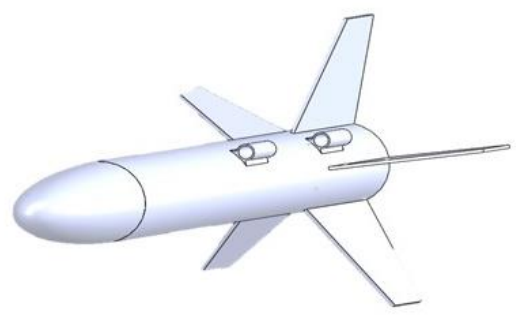

(c)

Fig. 5. Computer-aided drawing of presented Smokey SAM

Several rocket motor were tested in order to figure out the best thrust producer to meet the design requirement objective. As the target is to achieve Mach less than 0.2. List of tested rocket motor that are available in the OpenRocket database as in Table 2 . The database could be implemented in describing a scheme and design to promptly evaluate a model rocket engine's thrust curve, adopting a computer data logger and force examination.

Table 2

Tested rocket motor for the designed Smokey SAM

\begin{tabular}{llllll}
\hline Parameter & \multicolumn{5}{l}{ Single-use motor } \\
\cline { 2 - 6 } & AeroTech E15 & AeroTech D21 & Apogee C10 & Quest C6 & Estes E16 \\
\hline Manufacturer & AeroTech & AeroTech & Apogee & Quest & Estes \\
Designation & E15W-4 & D21-7 & C10-4 & C6-5 & E16-4 \\
Total Impulse (Ns) & 40 & 20.00 & 10.00 & 9.00 & 34.00 \\
Diameter (cm) & 2.40 & 1.80 & 1.80 & 1.80 & 2.90 \\
Length (cm) & 7.00 & 7.00 & 5.00 & 7.00 & 11.40 \\
\hline
\end{tabular}

\subsection{Computational Fluid Dynamics of Present Smokey SAM Rocket}

Drag also is a function of angle of attack, Mach number and Reynolds number. Generally, the magnitude of lift much higher compares to the magnitude of the drag. Thus it can be generated as lift-to-drag ratio L/D. It is a natural phenomenon where $C_{L}$ and $C_{D}$ depend on the wing orientation in the flow, such as the angle of attack.

The geometry of rocket was imported from SolidWork into Ansys Fluent. While for the control volume sizing, the size is selected according to the distance from the total rocket length and needed to be very far from the wing that act as a far field around the wing. Figure shows overall sizing for control volume and the geometry will have imported in Ansys. The geometry was then clarified as one solid body by using Ansys Design Modeler "Boolean" feature as shown in Figure 6. 


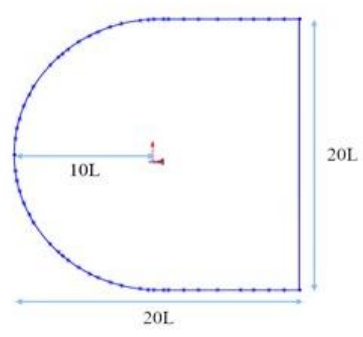

(a)

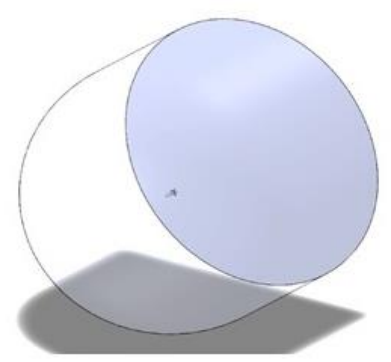

(b)

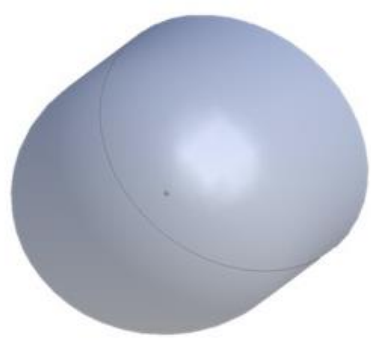

(c)

Fig. 6. Enclosure on presented Smokey SAM model

The geometry was then moved to the next process which is meshing. The applied meshing for the present computational model is solved by using tetrahedron elements, demonstrated in Figure 7. The applied feature is much more straightforward and could resolve complex geometry for the current rocket model. The inflation layer used in meshing is set to first layer thickness. The value of wall distance is calculated from $y+$ calculator by inserting the freestream velocity. The values of $y+$ and $\mathrm{Re}$ for both fin and body configuration are as shown in Table 3. With all the configurations has done, the total nodes are 288318 while the total of elements are 953437.

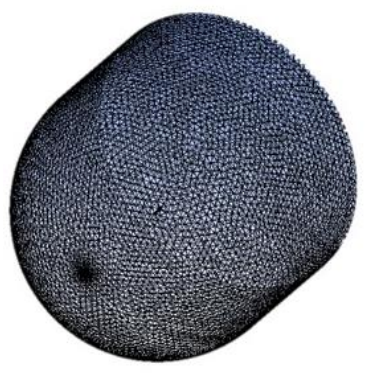

(a)

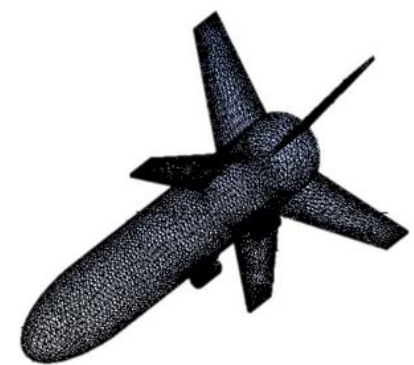

(b)

Fig. 7. Meshing element on presented Smokey SAM model

Table 3

Present model element meshing parameters

\begin{tabular}{lllll}
\hline Fin: Length $=0.07 \mathrm{~m}$, Area $=0.003403 \mathrm{~m}^{2}$ \\
\hline Kinematic viscosity, $\mu$ & Density, $\rho\left(\mathrm{kg} / \mathrm{m}^{3}\right)$ & Velocity, $\mathrm{V}(\mathrm{m} / \mathrm{s})$ & $\mathrm{y}^{+},(\mathrm{m})$ & $\mathrm{Re}$ \\
\hline $1.508 \times 10^{-5}$ & 1.178 & 54.60 & $5.059 \times 10^{-6}$ & $2.986 \times 10^{5}$ \\
& 40.00 & $6.754 \times 10^{-6}$ & $2.188 \times 10^{5}$ \\
& 25.00 & $1.045 \times 10^{-6}$ & $1.367 \times 10^{5}$ \\
\hline \multicolumn{5}{l}{ Body: Length $=0.37 \mathrm{~m}$, Area $=0.005346 \mathrm{~m}^{2}$} \\
\hline Kinematic viscosity, $\mu$ & Density, $\rho\left(\mathrm{kg} / \mathrm{m}^{3}\right)$ & Velocity, $\mathrm{V}(\mathrm{m} / \mathrm{s})$ & $\mathrm{y}^{+},(\mathrm{m})$ & $\mathrm{Re}$ \\
\hline $1.508 \times 10^{-5}$ & 1.178 & 54.60 & $5.698 \times 10^{-6}$ & $1.578 \times 10^{6}$ \\
& & 40.00 & $7.607 \times 10^{-6}$ & $1.156 \times 10^{6}$ \\
& 25.00 & $1.17710^{-6}$ & $7.227 \times 10^{5}$ \\
\hline
\end{tabular}

The shear stress transport K-omega model is the only variation of the standard $\mathrm{k}$ omega model available in Ansys-Fluent. K-omega model is the modification of the standard k-epsilon model. This model measures the turbulent viscosity to reckon for the transport of the principal turbulent shear 
stress. It also consolidates a cross-diffusion term in the $\omega$ equalisation and a blending function to concede precise computation of the near-wall and far-field areas.

The blending function triggers the conventional K-Omega model in near-wall regions and generates the K-Epsilon-like model in fields off the surface. The SST model's particular distinctions are more well-defined for a broader diversity of flows than the standard model. Comparable to the standard K-Omega model, the transport equations for $k$ and $\omega$ are somewhat transformed and are provided by

$\frac{\partial}{\partial t}(\rho k)+\frac{\partial}{\partial x_{i}}\left(\rho k u_{i}\right)=\frac{\partial}{\partial x_{j}}\left[\left(\mu+\frac{\mu_{t}}{\sigma_{k}}\right) \frac{\partial k}{\partial x_{j}}\right]+\widetilde{G_{k}}-Y_{k}+S_{k}$

$\frac{\partial}{\partial t}(\rho \omega)+\frac{\partial}{\partial x_{i}}\left(\rho \omega u_{i}\right)=\frac{\partial}{\partial x_{j}}\left[\left(\mu+\frac{\mu_{t}}{\sigma_{\omega}}\right) \frac{\partial \omega}{\partial x_{j}}\right]+G_{\omega}-Y_{\omega}+D_{\omega}+S_{\omega}$

where $\rho$ is the air density, $G_{k}$ depicts the formation of turbulent kinetic energy the arises due to mean velocity inclinations, $G_{\omega}$ is generation of $\omega$, and $Y_{k}$ and $Y_{\omega}$ express the dissipation of $k$ and $\omega$ due to turbulence (unsteady flow), $S_{k}$ and $S_{\omega}$ are the user defined function, while $D_{\omega}$ is the crossdiffusion expression. $\widetilde{G_{k}}$ is the turbulent kinetic energy term that is used to estimate a slightly different compared to other model as defined in Eq. (5)

$\widetilde{G_{k}}=\min \left(G_{k}, 10 \rho \beta * k \omega\right)$

where $\beta$ is the thermal expansion coefficient of air.

\section{Results}

\subsection{Methodology Validation}

This research follows the methodology in terms of aerodynamic evaluation as demonstrated in the study of Dahalan et al., [17]. Figure 8 presents the result of the drag coefficient of the present approach with the reference. Based on this plot, the CFD approach proposed is almost similar with less error compared to the CFD results by Dahalan et al., [17] for the same model. Hence, the scheme is validated throughout the computational and experimental procedure.

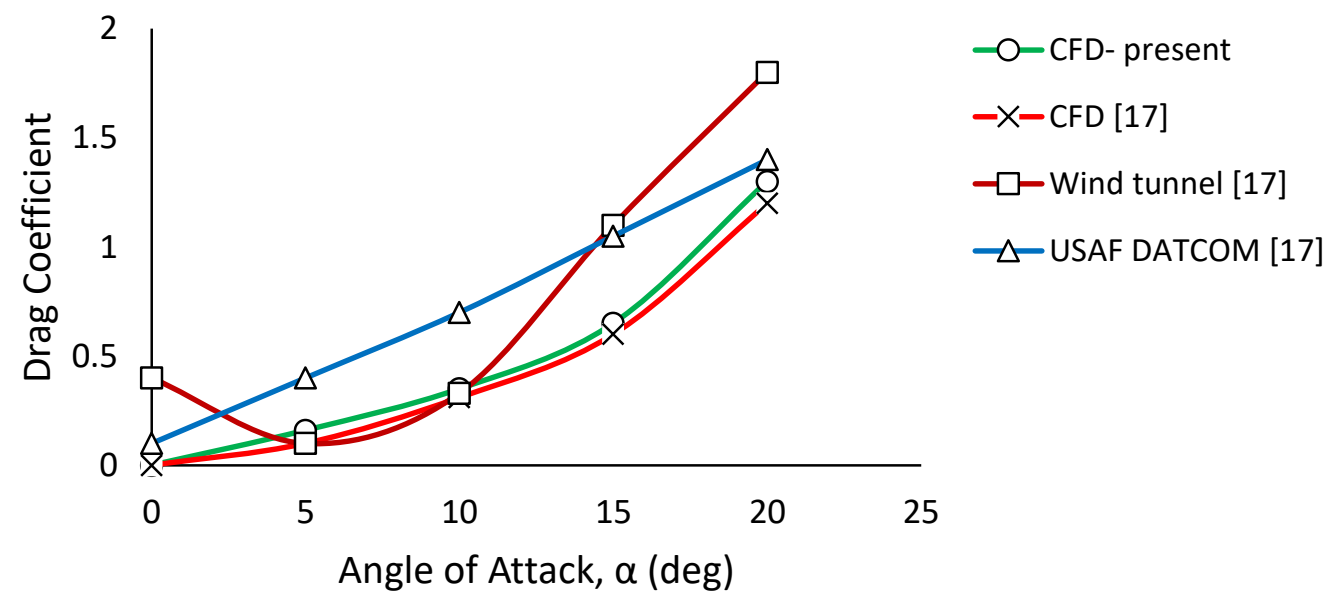

Fig. 8. Procedure validation of present approach with [17] 


\subsection{Velocity Flow Distribution}

As for the rocket fin analysis, overall, the maximum velocity increased by approximately $6 \%$ by considering the airflow behaviour. As for $54.6 \mathrm{~m} / \mathrm{s}$ demonstrated in Figure 9 (a), the maximum velocity reached is $57.6 \mathrm{~m} / \mathrm{s}$. While for $40 \mathrm{~m} / \mathrm{s}$ in Figure 9 (b), the flow can go up until $42.61 \mathrm{~m} / \mathrm{s}$ and as for 25 $\mathrm{m} / \mathrm{s}$. Observation is made that the maximum reached is up until $26.04 \mathrm{~m} / \mathrm{s}$, as shown in Figure 9 (c). It can be noticed that the velocity at the leading edge and the trailing edge of the fin are almost equivalent, and this also verify the no-slip condition theory where the fluid velocity at all fluid-solid boundaries is equal to that of the solid boundary.

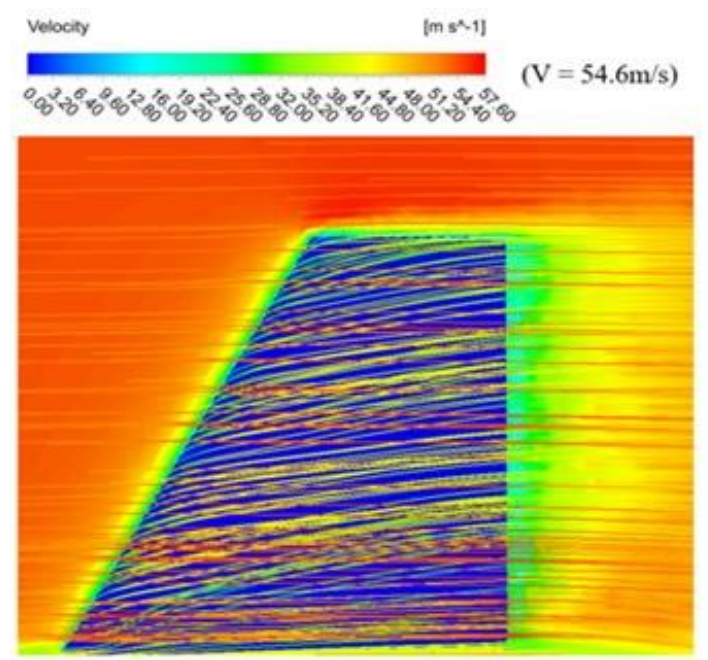

(a)
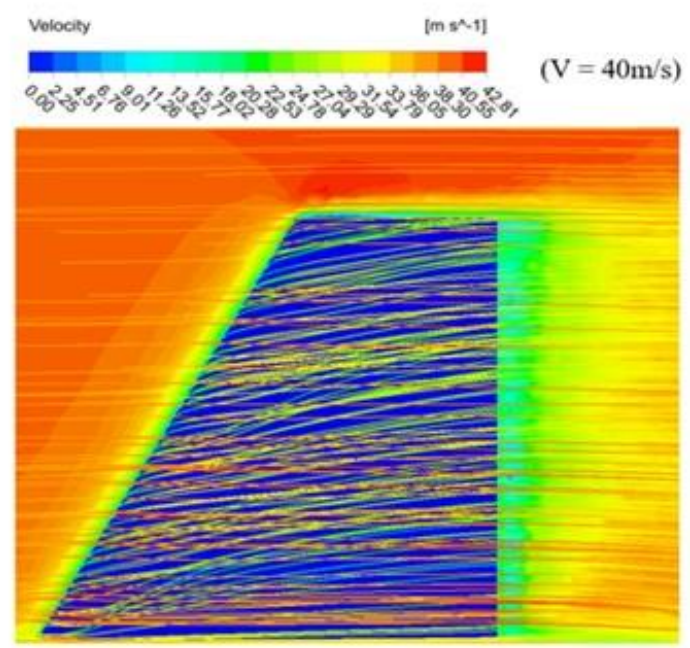

(b)
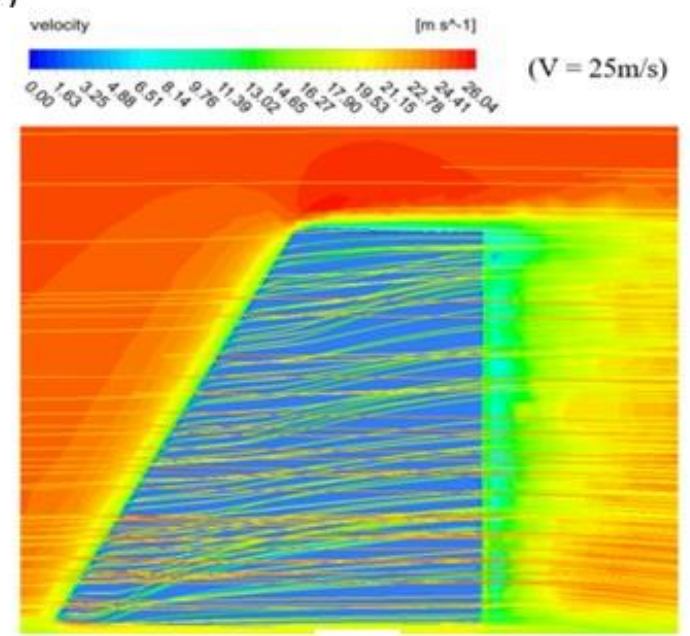

(c)

Fig. 9. Velocity contour at fin for (a) $V=54.6 \mathrm{~m} / \mathrm{s},(\mathrm{b}) \mathrm{V}=40 \mathrm{~m} / \mathrm{s}$, and (c) $V=25 \mathrm{~m} / \mathrm{s}$

For the Smokey SAM slender body analysis, the trend of velocity increment is just the corresponding as fin examination; the maximum velocity is found to rise around $6 \%$ considering the open-air flow behaviour. The maximum velocity reached as for $V=54.6 \mathrm{~m} / \mathrm{s}$ is about $57.6 \mathrm{~m} / \mathrm{s}$ in Figure $10(\mathrm{a})$, and $42.8 \mathrm{~m} / \mathrm{s}$ for $\mathrm{V}=40 \mathrm{~m} / \mathrm{s}$ in Figure 10 (b). It has also been identified that a slight increment of velocity for $V=25 \mathrm{~m} / \mathrm{s}$, as the maximum velocity reach is $26.57 \mathrm{~m} / \mathrm{s}$ in Figure 10 (c). 


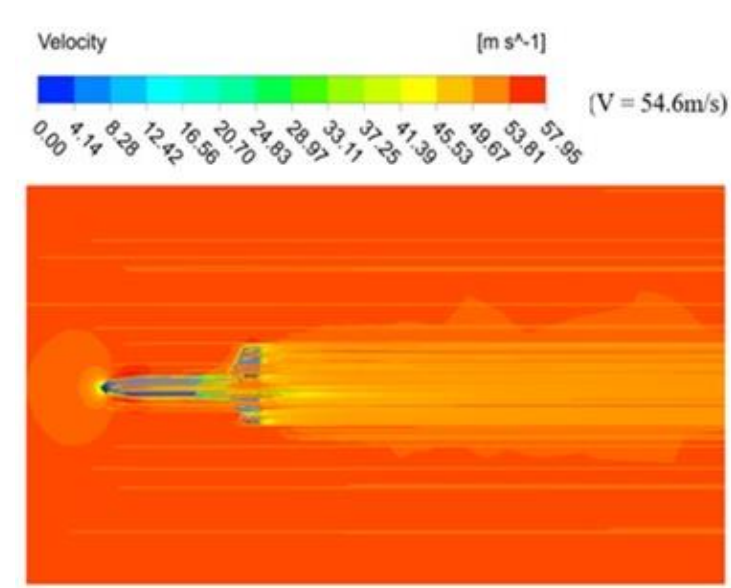

(a)
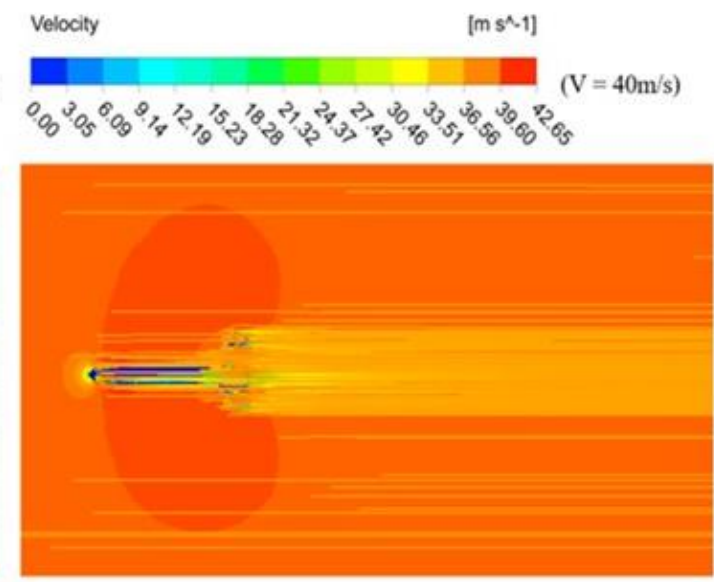

(b)

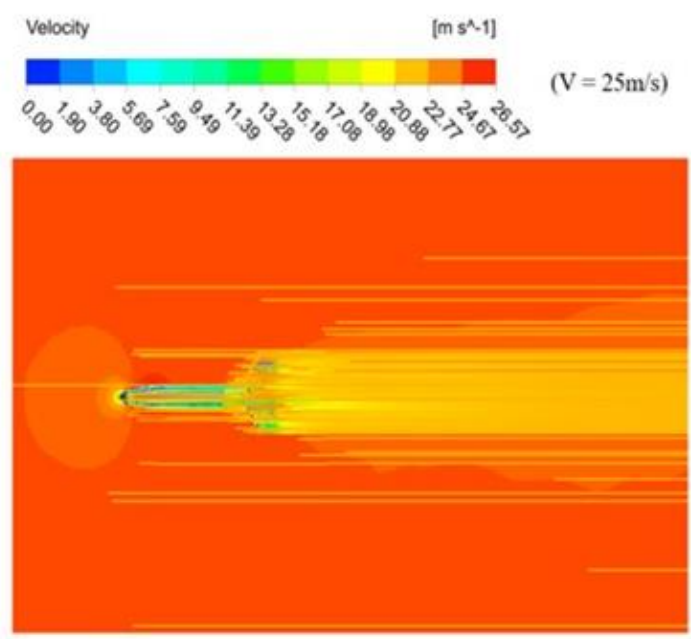

(c)

Fig. 10. Velocity contour of whole rocket body for (a) $V=54.6 \mathrm{~m} / \mathrm{s}$, (b) $V=40 \mathrm{~m} / \mathrm{s}$, and (c) $V$ $=25 \mathrm{~m} / \mathrm{s}$

\subsection{Pressure Distribution}

For pressure analysis on the body, the maximum pressure reached for the body at $V=54.6 \mathrm{~m} / \mathrm{s}$ is $1.48 \mathrm{kPa}$ n Figure 11 (a). While at $\mathrm{V}=40 \mathrm{~m} / \mathrm{s}$, the pressure can reach up until 792Pa shown in Figure 11 (b) and $313 \mathrm{~Pa}$ at $\mathrm{V}=25 \mathrm{~m} / \mathrm{s}$ in Figure 11 (c). The overall pressure distribution of the rocket body is still in an optimum condition except for the nose cone area, where it can be seen that it sustained high pressure because the nose cone is the first part that reaches the highest velocity than the rest of the components.

For pressure analysis on the rocket body, the maximum pressure reached $\mathrm{V}=54.6 \mathrm{~m} / \mathrm{s}$ is $1480 \mathrm{~Pa}$ in Figure 12 (a). While at $V=40 \mathrm{~m} / \mathrm{s}$, the pressure can reach up until $792 \mathrm{~Pa}$ in Figure $12(\mathrm{~b})$ and 313 $\mathrm{Pa}$ at $\mathrm{V}=25 \mathrm{~m} / \mathrm{s}$ in Figure 12 (c). The overall pressure distribution of the rocket body is still in an optimum condition except for the nose cone area, where it can be seen that it sustained high pressure because the nose cone is the first part that reaches the highest velocity than the rest of the components. The results of lift, drag and moment coefficients are summarised in Tables 4 and 5 for the fin and body components, respectively. 


\section{Table 4}

Aerodynamics evaluation of present Smokey SAM fin component

\begin{tabular}{lllllll}
\hline Velocity, V & Lift, & Lift Coefficient, & Drag, & Drag Coefficient, & Moment, & Moment Coefficient, \\
$\mathrm{m} / \mathrm{s}$ & $\mathrm{N}$ & $C_{L}$ & $\mathrm{~N}$ & $C_{D}$ & $\mathrm{~N} . \mathrm{m}$ & $C_{m}$ \\
\hline 54.60 & 0.049 & 0.00822 & 0.274 & 0.0232 & 0.023 & 0.056 \\
40.00 & 0.026 & 0.00810 & 0.153 & 0.0227 & 0.013 & 0.057 \\
25.00 & 0.010 & 0.00788 & 0.062 & 0.0223 & 0.005 & 0.057 \\
\hline
\end{tabular}

Table 5

Aerodynamics evaluation of present Smokey SAM body component

\begin{tabular}{lllllll}
\hline Velocity, V & Lift, & Lift Coefficient, & Drag, & Drag Coefficient, & Moment, & Moment Coefficient, \\
$\mathrm{m} / \mathrm{s}$ & $\mathrm{N}$ & $C_{L}$ & $\mathrm{~N}$ & $C_{D}$ & $\mathrm{~N} . \mathrm{m}$ & $C_{m}$ \\
\hline 54.60 & 0.166 & 0.00177 & 2.092 & 0.0497 & 0.026 & 0.00074 \\
40.00 & 0.089 & 0.00176 & 1.146 & 0.0478 & 0.014 & 0.00075 \\
25.00 & 0.032 & 0.00164 & 0.457 & 0.0459 & 0.005 & 0.00062 \\
\hline
\end{tabular}

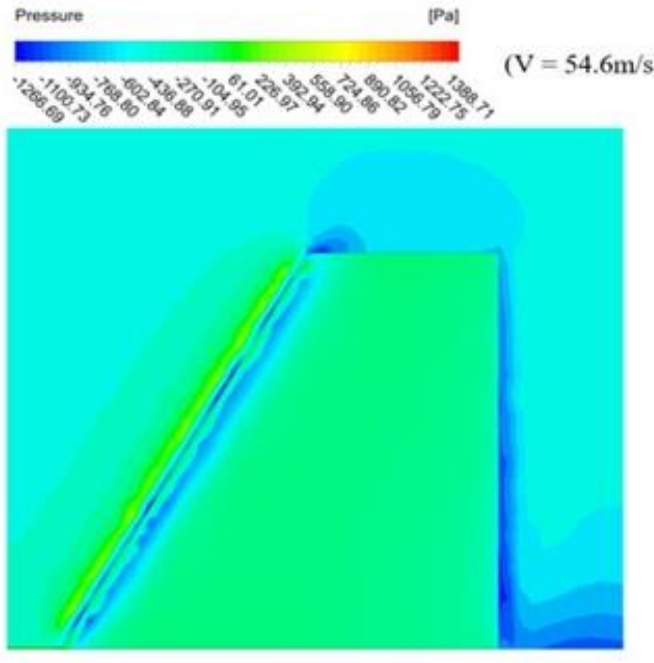

(a)

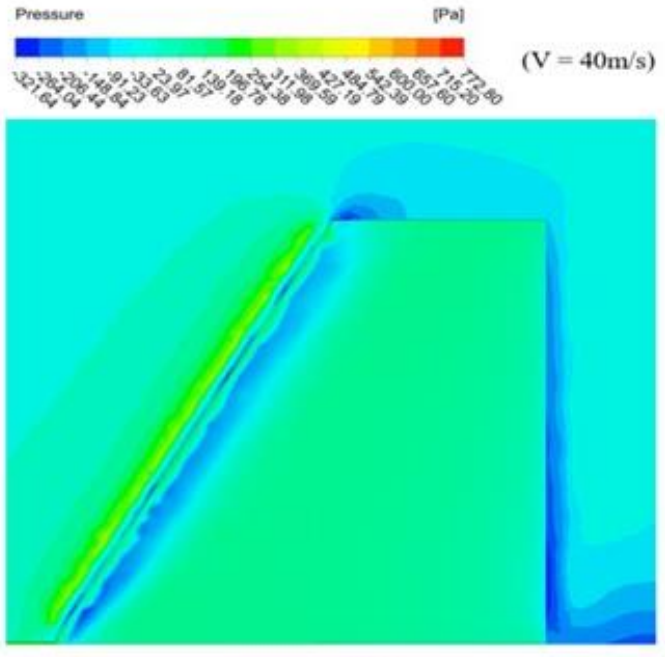

(b)

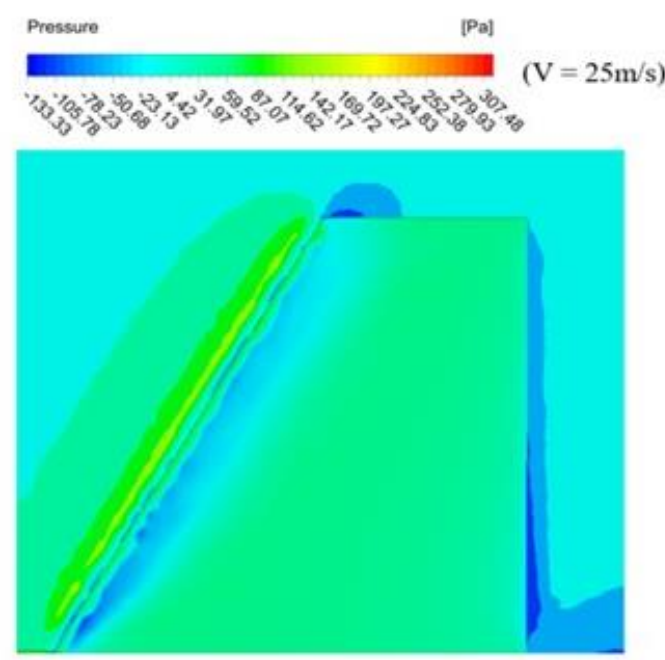

(c)

Fig. 11. Pressure distribution at body for (a) $V=54.6 \mathrm{~m} / \mathrm{s}$, (b) $V=40 \mathrm{~m} / \mathrm{s}$, and (c) $V=25 \mathrm{~m} / \mathrm{s}$ 


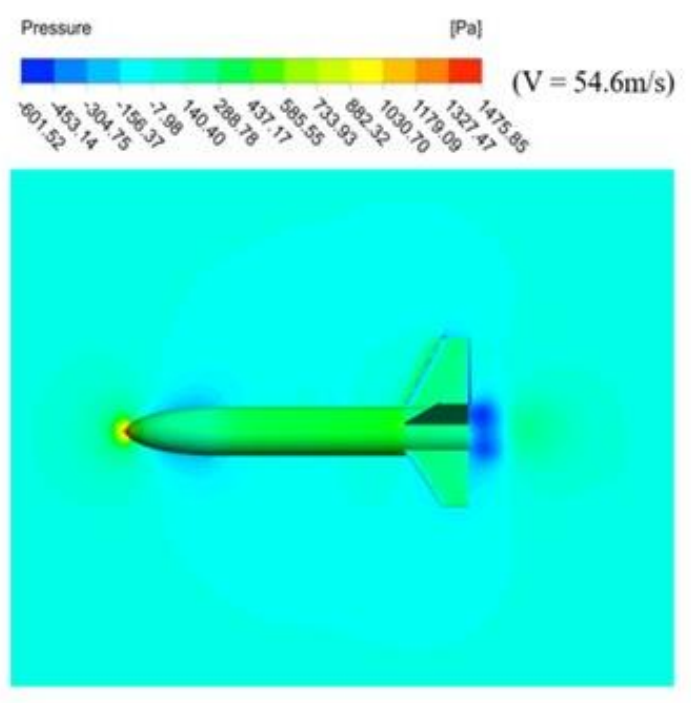

(a)

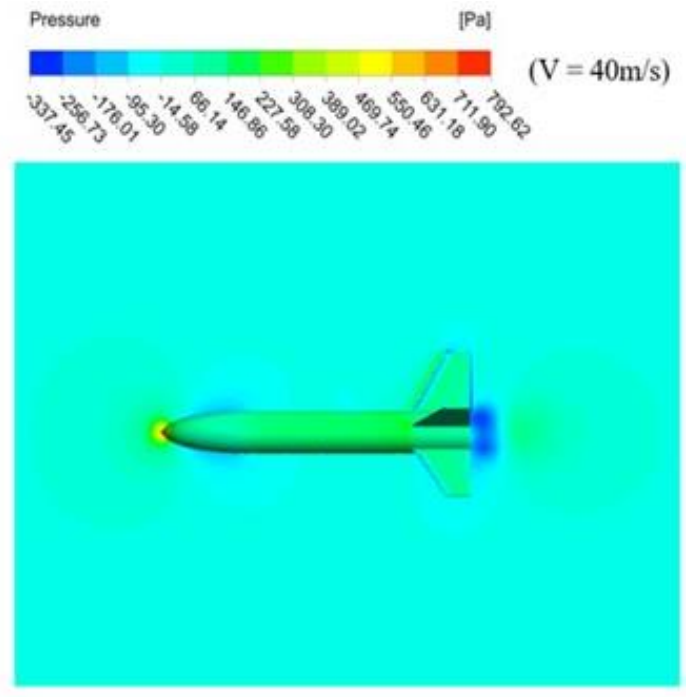

(b)

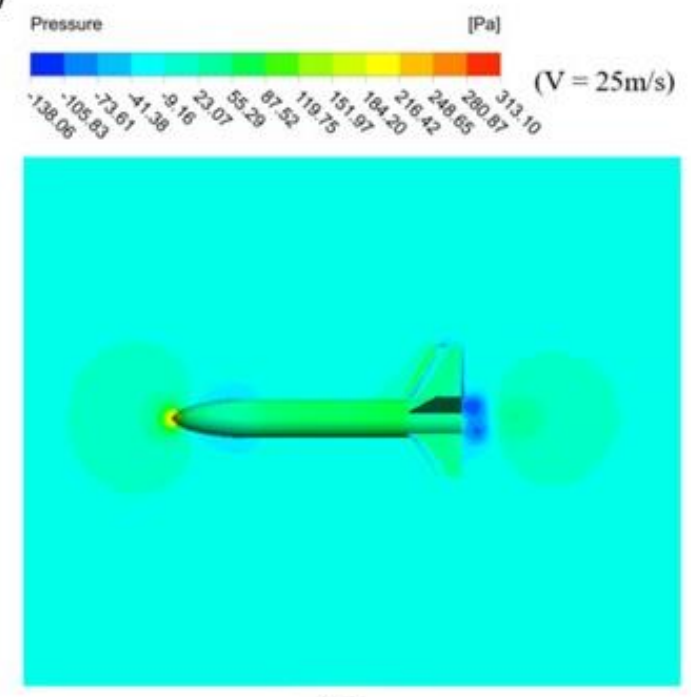

(c)

Fig. 12. Pressure distribution at body for (a) $V=54.6 \mathrm{~m} / \mathrm{s}$, (b) $V=40 \mathrm{~m} / \mathrm{s}$, and (c) $V=25 \mathrm{~m} / \mathrm{s}$

\subsection{Relevant Environmental Test(TRL-6)}

Meanwhile, the moment coefficient is almost constant for all the speeds used. This undertaking validates the theory that at the aerodynamic centre, the moment is constant; thus, no rotation will happen. As can be observed too, the lift coefficient is minimal and significant to zero; thus, this ensures the fin will not generate any lift that can cause any rotation to the rocket and assure it preference to have a steady flight upwards.

A moment is a force that measures its tendency to cause a body to rotate about a specific point or axis. This matter is different from the tendency for a body to move or translate in the direction of the force. For a moment to be developed, the force must act upon the body in such a manner that the body would begin to twist. For instance, this situation mostly occurs every time a force is applied to pass through the centroid of the body. A moment is due to a force not having an equal and opposite force directly along its line of action. The aerodynamic moment occurs when there is rotation at a particular point where one last thing to consider is the centre of pressure. The centre of pressure, $X_{c_{p}}$, is the average location of all the pressure acting upon a body moving through a fluid. 
As a rocket moves through the atmosphere, the air velocity varies around the surface of the rocket. This variation of air velocity produces a variation in the local pressure at various places on the rocket.

A real time flight test was conducted after the designed rocket has been fabricated using a 3D printer. The rocket motor was prepared in the lab and was used for the flight test validation. The test was conducted at a large area since the movement prediction of the rocket is going to be very fast and the projection is big. A launcher and an igniter were designed as well in order to conduct the flight test. The setup for the flight test is as in Figure 13.

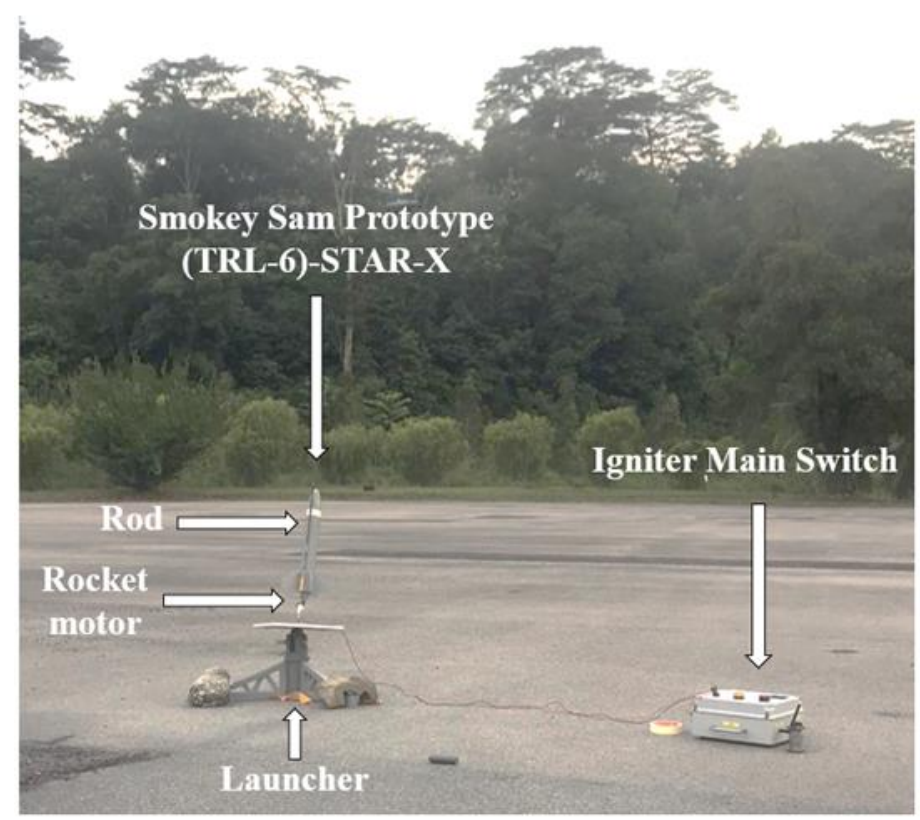

Fig. 13. Pressure distribution at body for (a) $V=54.6 \mathrm{~m} / \mathrm{s}$, (b) $V=40 \mathrm{~m} / \mathrm{s}$, and (c) $V=25 \mathrm{~m} / \mathrm{s}$

Several observations can be made from the conducted flight test configuration setup

i. The rod attached to the rocket is quite agile and does not stay static for the rocket to leave the rod. This situation will cause instability for the rocket when it leaves the rod.

ii. The igniter cable setup was relatively short, and any failure such as a rocket explosion will damage the main igniter switch.

iii. The igniter attached to the rocket motor was only a pure chrome wire configuration; thus, to start the burning of the motor took a bit longer than it should be.

The best configuration is to coat it with a black powder solution to create a good flame for the rocket motor to start burning. As stated before, the rocket launcher was considerably agile while the rocket is leaving it. The rocket moved a little bit down when leaving the rocket launcher, but the rocket managed to have a stable flight condition despite the instability when leaving the rocket launcher. For instance, the rocket managed to stabilise itself when flying; thus, this situation attests to the CFD simulation where the aerodynamics forces acting on it are more trivial, thus ensuring the rocket had an excellent and stable flight path. The flight test validations are shown in Figure 14. 


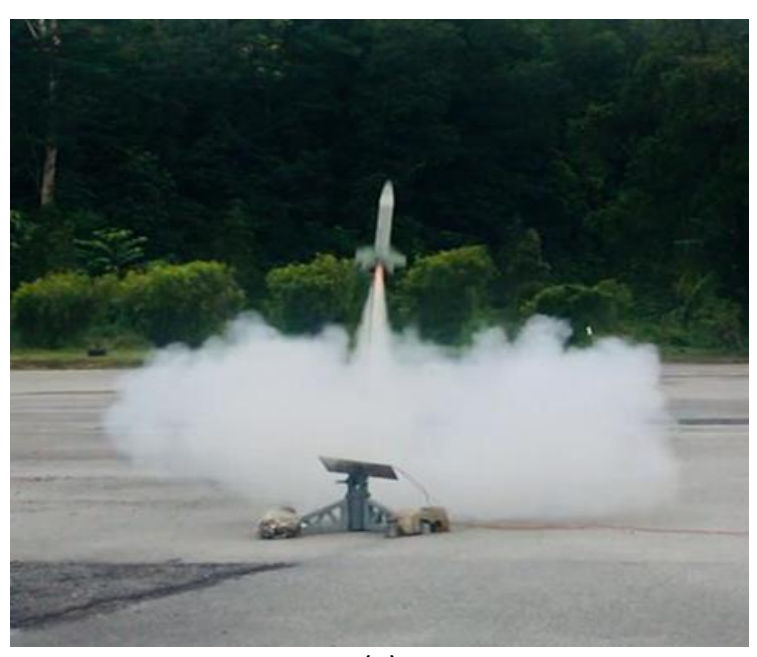

(a)

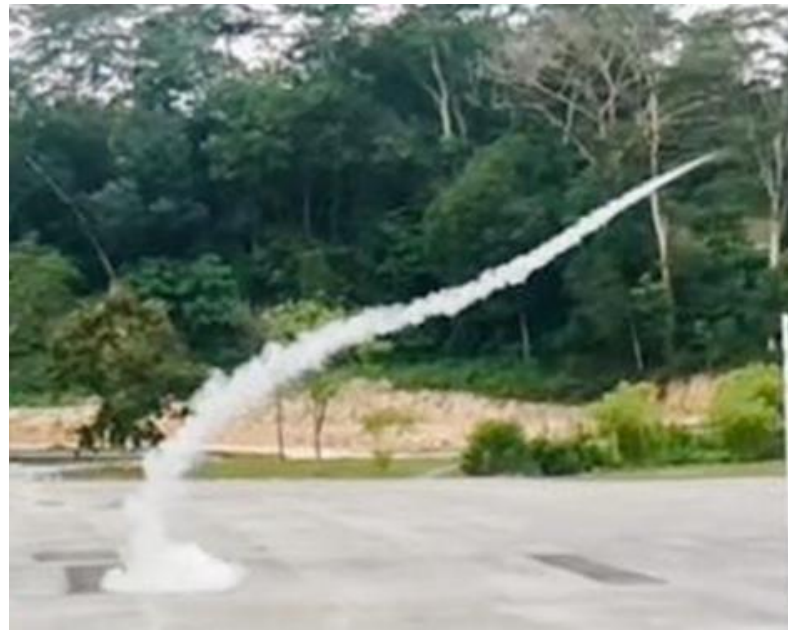

(b)

Fig. 14. Smokey SAM rocket (a) once leaving the launcher, (b) flight trajectory at angle

In rocket analysis, the centre of pressure is essential for predicting the flight stability of a rocket. For positive stability in rockets, the centre of pressure must be further away from the nose than the centre of gravity. This action ensures that any increased forces resulting from an increased angle of attack result in an increased restoring moment to drive the rocket back to the trimmed position. A positive static margin suggests that the complete rocket makes a restoring moment for any angle of attack from the trim position in rocket analysis [20].

\section{Conclusions}

This paper intends to study the rocket's flow behaviour once it is launched since the aerodynamics analysis on the Smokey SAM prototype rocket has not been comprehensively examined. The aerodynamics loads acting on the rocket body must ensure that a steady flight condition can be achieved. To sum up the CFD simulation work, the setup for the CFD simulation was a success since the results are converged. As for a low-speed trajectory, the pressure acting on the fin is less compared to a high-speed trajectory, and this is valid since, at low speed, the pressure is less considering the movement of air particles is much slower than at high speed. The fin and the body flow distribution showed the same trend where the simulation recorded that as the speed increases, the pressure also increases. It is shown that fins contributed to the aerodynamics load higher than the body, and this is reliable since the fin acts as the stabiliser for the rocket in mid-air.

\section{Acknowledgement}

This research is funded through a consultation project by Lestari Aero Industries Sdn Bhd, Title: Design \& Development of Smokey SAM Prototype (TRL-6) - STAR (X). Special thanks to Mr. Ahmad Joahari Abu Bakar and Ms Noriza Dani, CEO and COO of Lestari Aero Industries Sdn Bhd, respectively for the encouragement to the completion of this project.

\section{References}

[1] Matsuo, H., M. Kohno, J. Onoda, T. Kawashima, T. Murakami, and N. Onojima. "Development of the S-520 single stage sounding rocket." Acta Astronautica 9, no. 10 (1982): 631-635. https://doi.org/10.1016/00945765(82)90107-2

[2] Goto, Keisuke, Junpei Nishimura, Junichi Higashi, Haruna Taki, Takato Ukai, Yuki Hayamizu, Taihei Yamada et al. "Preliminary experiments on rotating detonation rocket engine for flight demonstration using sounding rocket." In 2018 AIAA Aerospace Sciences Meeting, p. 0157. 2018. https://doi.org/10.2514/6.2018-0157 
[3] Okninski, Adam, Blazej Marciniak, Bartosz Bartkowiak, Damian Kaniewski, Jan Matyszewski, Jan Kindracki, and Piotr Wolanski. "Development of the polish small sounding rocket program." Acta Astronautica 108 (2015): 46-56. https://doi.org/10.1016/j.actaastro.2014.12.001

[4] Kobald, Mario, Christian Schmierer, Ulrich Fischer, Konstantin Tomilin, and Anna Petrarolo. "A record flight of the hybrid sounding rocket heros 3." Transactions of the Japan Society for Aeronautical and Space Sciences, Aerospace Technology Japan 16, no. 3 (2018): 312-317. https://doi.org/10.2322/tastj.16.312

[5] Reasenberg, Robert D., Biju R. Patla, James D. Phillips, and Rajesh Thapa. "Design and characteristics of a WEP test in a sounding-rocket payload." Classical and Quantum Gravity 29, no. 18 (2012): 184013. https://doi.org/10.1088/0264-9381/29/18/184013

[6] Grosse, Jens, Stephan T. Seidel, Markus Krutzik, Marco Scharringhausen, and Tim van Zoest. "Thermal and mechanical design of the MAIUS atom interferometer sounding rocket payload." In AIAA SPACE 2014 Conference and Exposition, p. 4210. 2014. https://doi.org/10.2514/6.2014-4210

[7] Schkolnik, Vladimir, O. Hellmig, A. Wenzlawski, Jens Grosse, A. Kohfeldt, K. Döringshoff, A. Wicht et al. "A compact and robust diode laser system for atom interferometry on a sounding rocket." Applied Physics B 122, no. 8 (2016): 1-8. https://doi.org/10.1007/s00340-016-6490-0

[8] Wibawa, Lasinta Ari Nendra, Kuncoro Diharjo, Wijang Wisnu Raharjo, and Bagus H. Jihad. "Stress Analysis of ThickWalled Cylinder for Rocket Motor Case under Internal Pressure." Journal of Advanced Research in Fluid Mechanics and Thermal Sciences 70, no. 2 (2020): 106-115. https://doi.org/10.37934/arfmts.70.2.106115

[9] Wilcox, David C. "Formulation of the kw turbulence model revisited." AIAA journal 46, no. 11 (2008): $2823-2838$. https://doi.org/10.2514/1.36541

[10] Khalaji, E., M. R. Nazari, and Z. Seifi. "2D numerical simulation of impinging jet to the flat surface by $\$ \$ \mathrm{k}-\backslash \mathrm{omega-}$ loverline $\left\{\left\{v^{\wedge}\{2\}\right\}\right\}-f \$$ turbulence model." Heat and Mass Transfer 52, no. 1 (2016): $127-140$. https://doi.org/10.1007/s00231-015-1688-y

[11] Potapkin, A. V., and D. Yu Moskvichev. "Sonic boom generated by a slender body aerodynamically shaded by a disk spike." Shock Waves 28, no. 6 (2018): 1239-1249. https://doi.org/10.1007/s00193-018-0817-1

[12] Kumar, P., and J. K. Prasad. "Mechanism of side force generation and its alleviation over a slender body." Journal of Spacecraft and Rockets 53, no. 1 (2016): 195-208. https://doi.org/10.2514/1.A33290

[13] Obeid, Osama, Ibraheem AlQadi, and Jaber AlMutairi. "Investigation of asymmetric flow past a slender body at high angles of attack." Theoretical and Computational Fluid Dynamics 33, no. 5 (2019): $481-508$. https://doi.org/10.1007/s00162-019-00503-0

[14] Chima, R. O. D. R. I. C. K. V. "A k-omega turbulence model for quasi-three-dimensional turbomachinery flows." In 34th Aerospace Sciences Meeting and Exhibit, p. 248. 1995. https://doi.org/10.2514/6.1996-248

[15] López, Deibi, Diego Domínguez, and Jesús Gonzalo. "Impact of turbulence modelling on external supersonic flow field simulations in rocket aerodynamics." International Journal of Computational Fluid Dynamics 27, no. 8-10 (2013): 332-341. https://doi.org/10.1080/10618562.2013.867951

[16] Aolin, Chen, A. A. Al Mayas, Faieza Abdul Aziz, Noorfaizal Yidris, and Kamarul Arifin Ahmad. "Investigation of Solid Propellant Rocket Motor Nozzle via CFD Simulation." Journal of Advanced Research in Fluid Mechanics and Thermal Sciences 68, no. 2 (2020): 1-8. https://doi.org/10.37934/arfmts.68.2.18

[17] Dahalan, Md Nizam, Ahmad Fitri Suni, Iskandar Shah Ishak, Nik Ahmad Ridhwan Nik Mohd, and Shabudin Mat. "Aerodynamic study of air flow over a curved fin rocket." Journal of Advanced Research in Fluid Mechanics and Thermal Sciences 40, no. 1 (2017): 46-58.

[18] Menter, Florianr. "Zonal two equation kw turbulence models for aerodynamic flows." In 23rd fluid dynamics, plasmadynamics, and lasers conference, p. 2906. 1993. https://doi.org/10.2514/6.1993-2906

[19] LaBudde, Edward V. "Extending The Barrowman Method For Large Angles Of Attack." Westlake Village, CA, USA (1999).

[20] Hammargren, Kristoffer. "Aerodynamics Modeling of Sounding Rockets: A Computational Fluid Dynamics Study." Luleå University of Technology, 2018. 